\title{
AFFECTIVE IMAGE OF SPA AND WELLNESS DESTINATION BULGARIA
}

\author{
Milena Stoyanova, Associate Professor $\mathrm{PhD}^{1}$ \\ DOI: https://doi.org/10.31410/tmt.2018.501
}

\begin{abstract}
The aim of the study is to estimate affective image of SPA and wellness destination Bulgaria. To assess the affective image, four semantic differential scales proposed by Russel and Pratt and seven additional author's scales are used, by which foreign tourists define their attitude to Bulgaria as a SPA and wellness destination. The findings of the study have significant managerial implications for destination marketing managers in SPA and wellness tourism.
\end{abstract}

Keywords: SPA and wellness destinations in Bulgaria, affective tourist image, bipolar dimensions, semantic differential

\section{INTRODUCTION AND LITERATURE REVIEW}

$\int \mathrm{n}$ [4], [1], [2], [12] it is shown that the image of a destination is considered as a key factor in taking travel decisions. The multilateral nature of Bulgarian image as a SPA and wellness destination is still a subject of research in order to determine how it has been formed and what the determinants of this process are. This process in turn will enable its effective advertising and its ability to take strong positions in Western receptive markets.

There have been a lot of studies on the image of a tourist destination so far. Terms such as "idea", "perception" or "mental performance" of a tourist destination are commonly used to give an idea about the image of a destination. It is mainly used as a subjective concept [3], [6], [9] as the reality of a tourist destination can be significantly different from the perceived image [7], [8], [13]. Therefore, there is need for identification of the aspects that tourists use to form the image of the destination as well as the role of psychological factors (internal factors) in order to improve the target market positioning of the destination.

It should be noted that in forming the destination image, managers should include not only its physical characteristics but also the whole set of emotions and feelings, which a destination can awaken in tourists' minds [10]. On the other hand, marketers need to understand that in order to influence the affective evaluations of a destination, they must take into account both its characteristics and tourists' motivations.

\section{OBJECTIVES}

For the purpose of the study, a questionnaire has been designed to gather primary information about Western European tourists' perceptions of Bulgaria as a tourist destination. The questionnaire assessing the image of Bulgaria as a SPA and wellness destination is consistent with the

Shumen University “Konstantin Preslavsky”, Department of Geography, Regional Development and Tourism, 115 Universitetska str., Shumen, Bulgaria 
imposed by Echtner and Ritchie's image framework [5], which uses a combination of open and closed questions in order to achieve a reliable picture of an image destination.

For the affective aspect of Bulgarian image as a SPA and wellness destination, it has been used eleven pairs of dimensions (Familiar/Unfamiliar; Famous /Unknown; Relaxing/Distressing; Pleasant/Unpleasant; Uplifting/Sleepy; Exciting/Gloomy; Hospitable/Inhospitable; Cheap/Expensive; High quality/Poor quality; Authentic/Inauthentic; Prestigious/Unprestigious) with five categories of the scales: respectively from 1 to 5 (Likert scale) where the distance of 1 answer of a respondent is closer to the opposite dimension. For the rest of the questions, it has been also used the five-point Likert scale, where 1 means "at least" and 5 "the most".

The results are processed with Microsoft ${ }^{\circledR}$ Excel $^{\circledR} 2010$, IBM $^{\circledR}$ SPSS $^{\circledR}$ Version 18, IBM $^{\circledR}$ SPSS $^{\circledR}$ Version $23^{\circledR}$.

\section{RESULTS}

The researched target group includes 460 foreign tourists, who visited Bulgarian SPA and wellness centers during the summer and autumn of 2015 and 2016.

The analysis of the socio-demographic profile shows some interesting facts that differ from the global trends of SPA and wellness tourists. Almost half of the respondents are not middle-aged. They are between 18 and 30 years old. The second is the group of 31 to 40 years old tourists. This fact, together with the fact that 35.5 percent of them have an annual income up to $€ 14,999$ and $22.10 \%$ are still students proves that Bulgaria attracts mainly young tourists. Another proof is that most of them - 29.7 percent undertake only one; 35\% - two trips outside the country in order to rest and for recreation purposes.

The gender breakdown is also interesting. Globally, more women than men practice SPA and wellness tourism. However, genders are divided almost equally here and even the equality is violated by $2.00 \%$ predominance by men. This shows a recent trend among men for health prevention and "well-being".

It has been confirmed that the imposed trend that Bulgarian SPA products are aimed primarily at people with higher education $-66.60 \%$ and secondary education $-28.20 \%$. Except students, the tourists are also mainly employees in private companies $-17.8 \%$, managers $-14.9 \%$ and $14 \%$ of SPA visitors are retired or they do not work.

Bulgarian SPA and wellness products are the most popular on British (27.70 \%), German (24.60 $\%)$, and Danish (10.50 \%) market. There is an interesting fact, which shows that the Bulgarian SPA products are becoming more popular - the third place is occupied by French SPA and wellness tourists and it reaches $13.10 \%$. It must be emphasized that 76.80 percent of all tourists that visited Bulgaria have already visited Bulgarian SPA centers.

To assess the affective image, the method of semantic differential is used, by which respondents define their attitude to Bulgaria as a SPA and wellness tourist destination. 


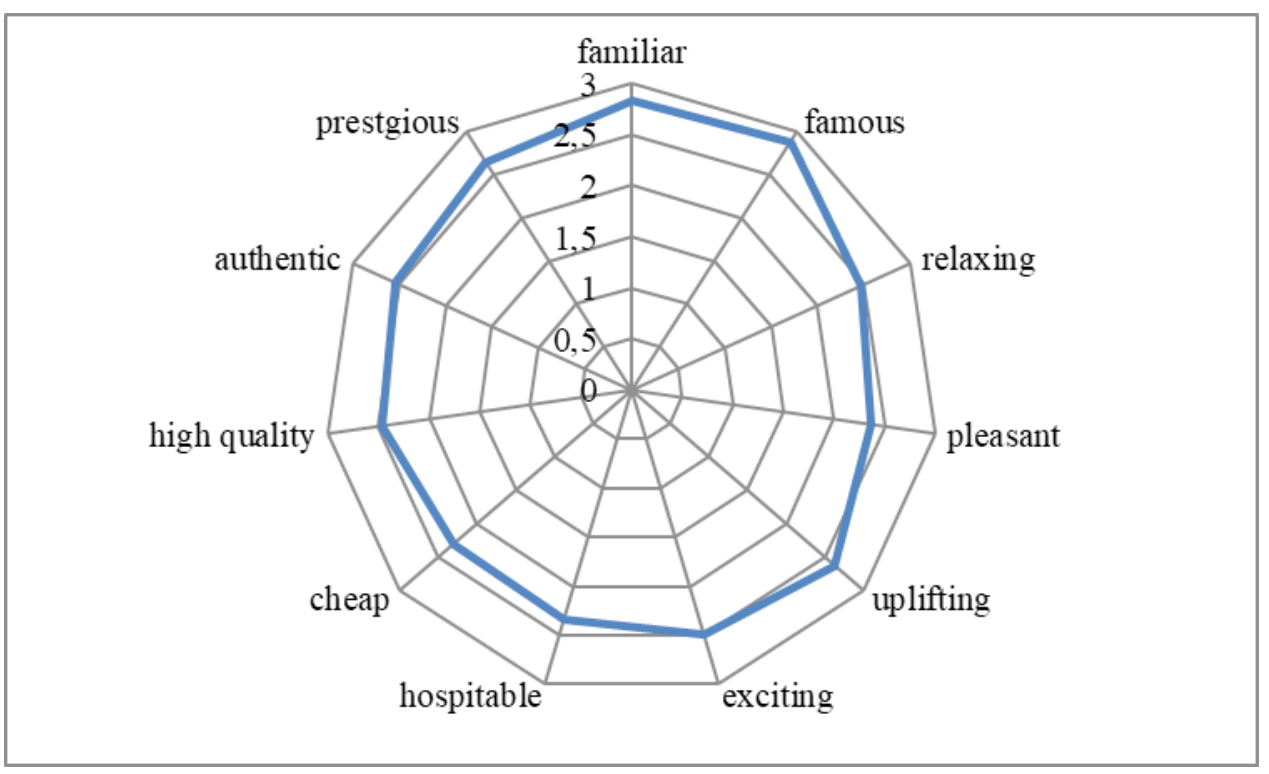

Figure 1: A polar graph for the affective tourist image of Bulgaria as a SPA and wellness destination

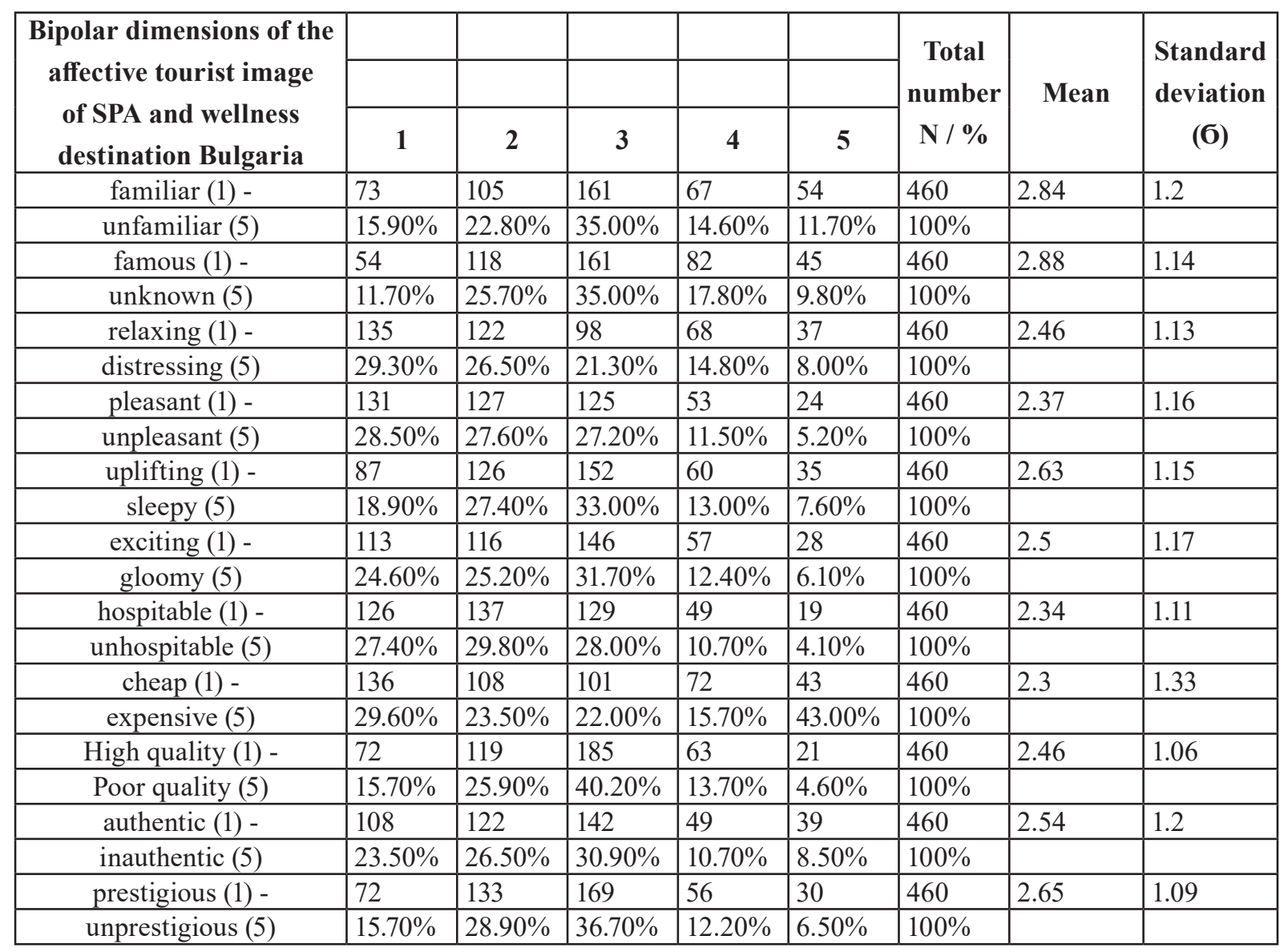

Table 1: Frequencies, means and standard deviations of the affective tourist image of SPA and wellness destination Bulgaria on the basis of eleven bipolar dimensions

The data from analysis of the frequencies, means and standard deviations of these eleven bipolar scales for the affective tourist image of Bulgaria, show that tourists perceive Bulgaria as a famous and familiar destination, SPA and wellness destination, respectively $38.70 \%$ and 37.40 
$\%$. Naturally, because these are SPA and wellness tourists, more than half of them accept it as a relaxing destination -257 people $(55.80 \%)$ and pleasant destination -258 people $(56.10 \%)$. Most of the respondents accept Bulgaria as neither exciting nor gloomy (average $=2.5$ ), but it is interesting that to most of them it is more exciting than relaxing and sleepy (average $=2.63$ or 46.3 percent). This probably is due to the fact that the SPA and wellness tourism is combined with other types of tourism in most of the cases.

The notorious fact that Bulgaria is a hospitable and cheap destination even for SPA and wellness tourism is confirmed by the values of these dimensions - respectively with means 2.34 and 2.3. However, for a significant number of the respondents $(40.00 \%)$, it emerged as a destination neither with the so high quality nor with low quality of these services.

As a whole Bulgaria seems to be more like a prestigious and authentic destination for SPA and wellness tourism, respectively with means 2.65 (standard deviation $=1.09)$ and 2.54 (standard deviation $=1.2$ ).

The diagram of the semantic differential of Bulgaria as a SPA and wellness destination clearly demonstrates that means for all tested bipolar pairs attributes are between 2.3 and 2.8, which proves that tourists have more positive affect to it. That fact, however, highlights Bulgaria's great potential which has to transform it into a fully recognizable destination for SPA and wellness tourism.

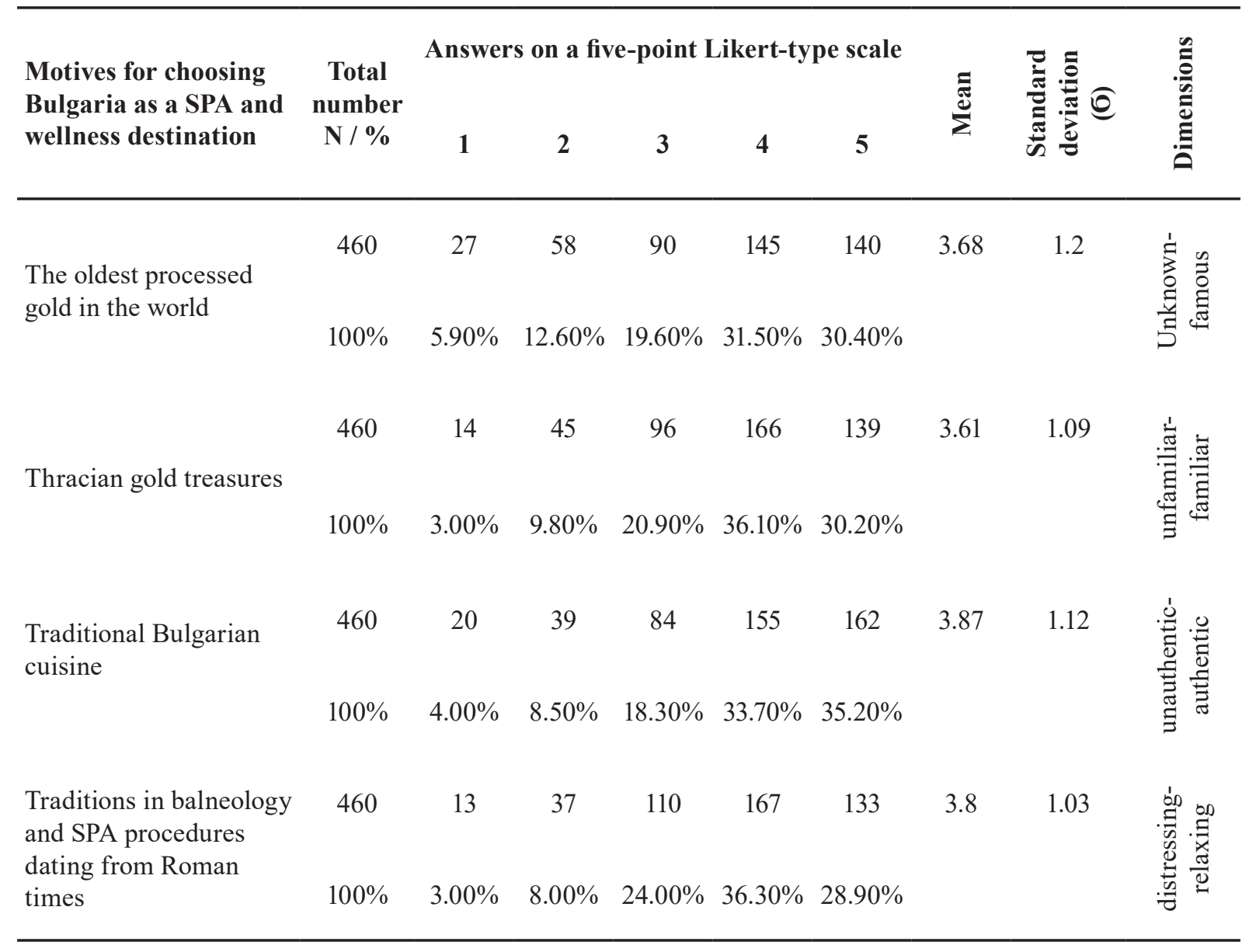

Table 2: Unknown-famous, unfamiliar-familiar, distressing-relaxing, unauthentic-authentic dimensions of the affective image according to the main motives for choosing SPA and wellness destination Bulgaria (on a five-point Likert-type scale) 


\section{Dimension 1 \\ familiar \\ famous \\ relaxing \\ pleasant \\ uplifting \\ exciting \\ hospitable \\ cheap \\ high quality authentic \\ prestigious}

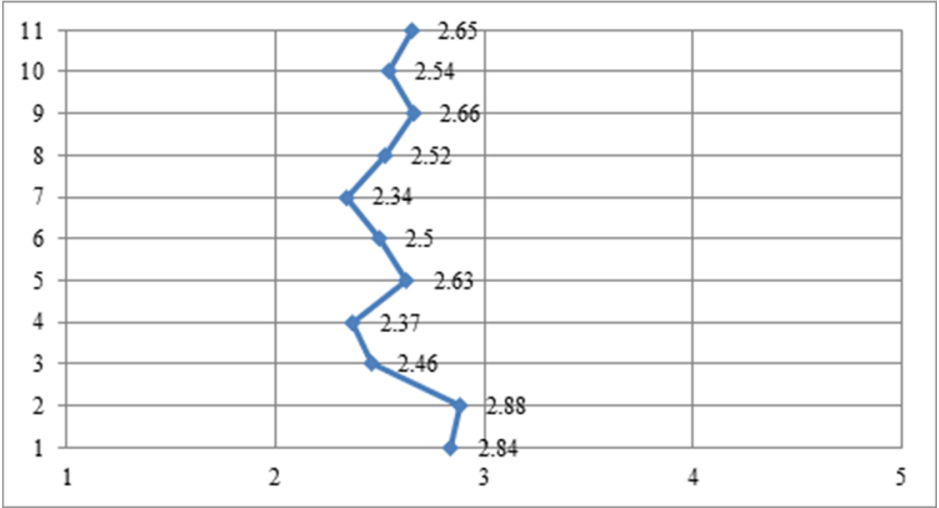

Dimension 2

unfamiliar

unknown

distressing

unpleasant

sleepy

gloomy

unhospitable

expensive

poor quality

inauthentic

unprestigious

5

Figure 2: Semantic differential of the affective image of SPA and wellness destination Bulgaria

According to [11] there is a relationship between the motives for choosing a destination and the main affective dimensions of its image. For that purpose, it has been also used the fivepoint Likert scale, where 1 means "at least" and 5 "the most", through which the respondents assess the main motives for choosing SPA and wellness destination Bulgaria, and those questions are connected to the main bipolar dimensions of the affective image of destinations.

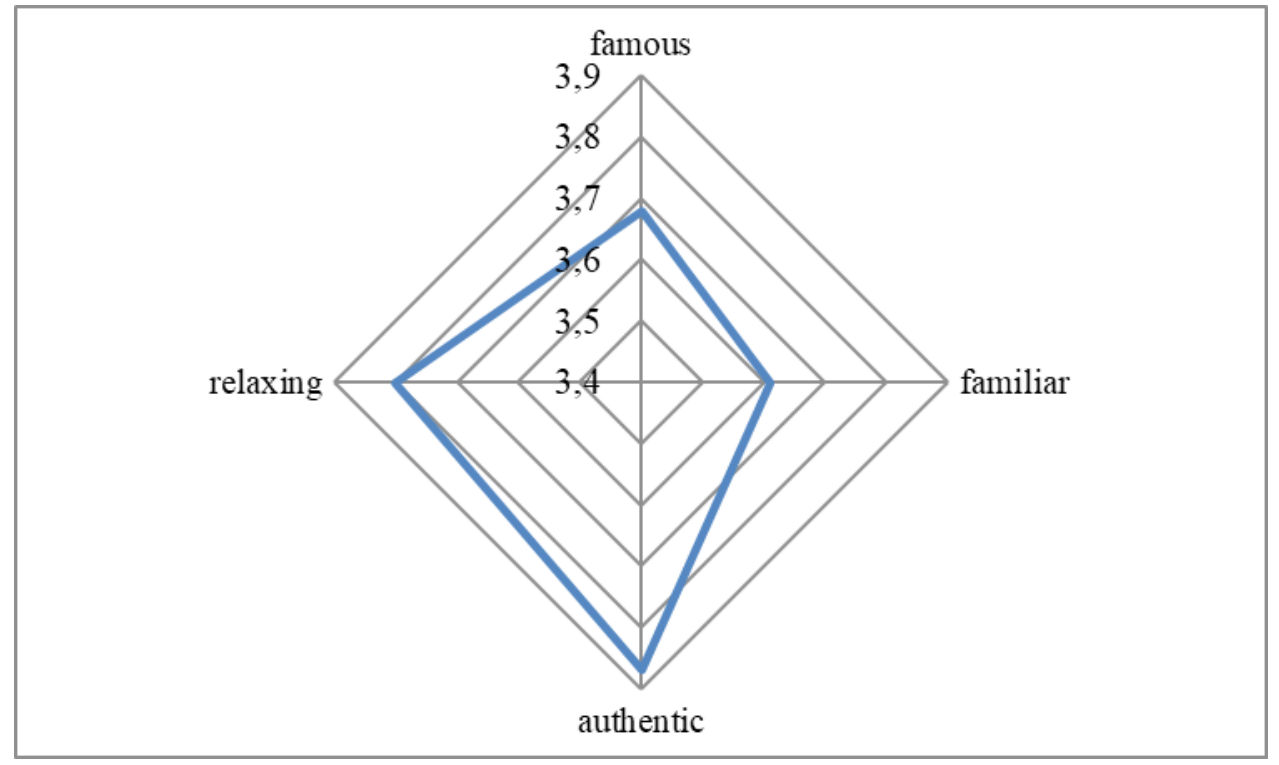

Figure 3: A polar graph for the affective tourist image of SPA and wellness destination Bulgaria (semantic differential scales unknown-famous, unfamiliar-familiar, distressing-relaxing, unauthentic-authentic dimensions)

Data show that more than a half of tourists evaluate with 4 and 5 grades, which indicates that they choose Bulgaria for SPA and wellness because it is famous (61.90\%), they know it $(66.30 \%)$ and find it as an authentic (68.90\%) and relaxing $(65.20 \%)$. 


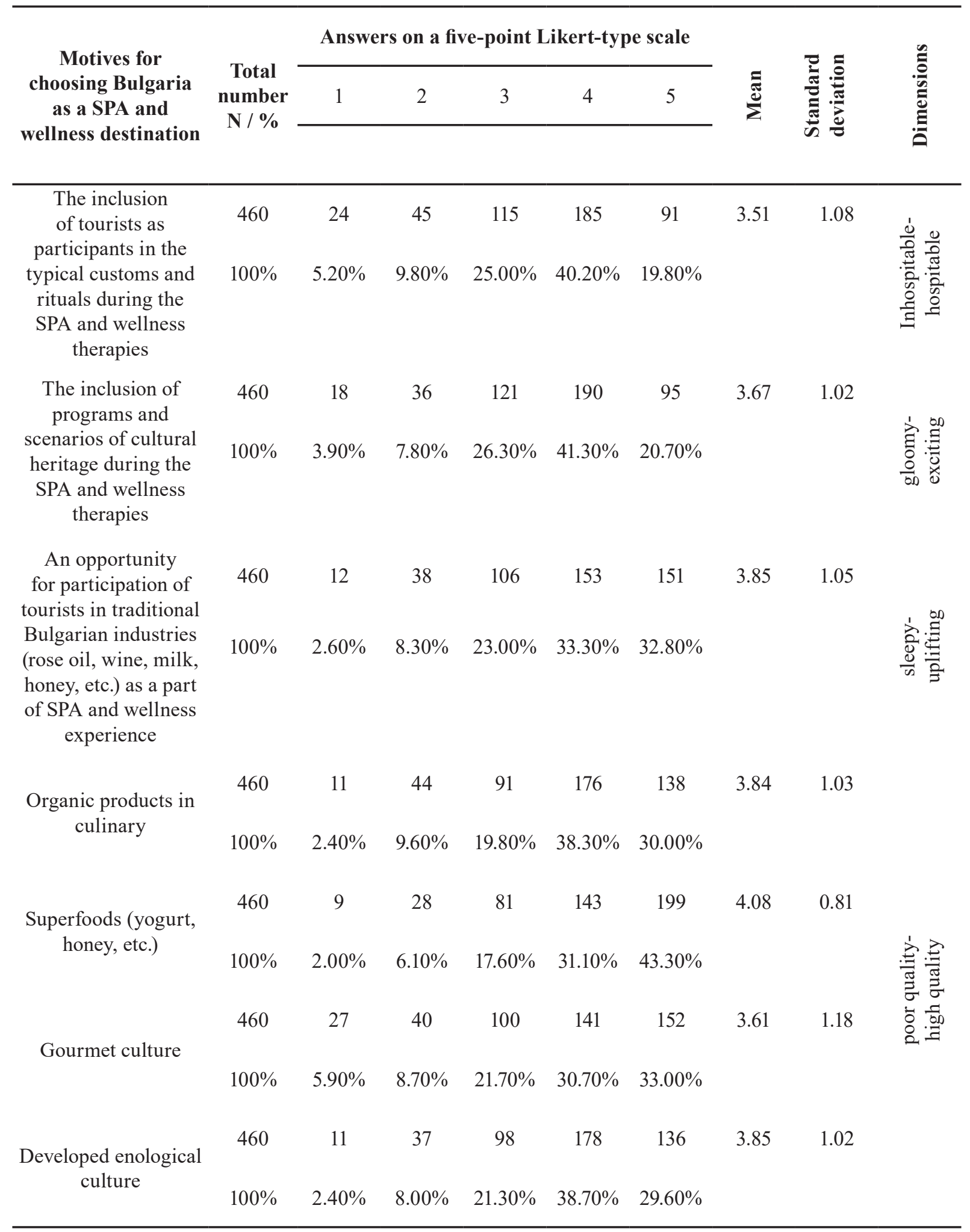

Table 3: Inhospitable-hospitable, gloomy-exciting, sleepy-uplifting, poor quality-high quality dimensions of the affective image according to the main motives for choosing SPA and wellness destination Bulgaria (on a five-point Likert-type scale)

Data about the other four bipolar dimensions show that SPA and wellness tourist choose Bulgaria because of the high quality of superfoods (342 or $74.40 \%$ ), organic products in culinary (314 or $68.30 \%$ ) and enological culture of destination (314 or $68.30 \%$ ), which is connected to the 
nature of the SPA and wellness and to the striving for ,well-being“. They reaffirm that the majority of respondents $(60.00 \%)$ like hospitality in the destination, but uncharacteristically SPA and wellness tourists find it more exciting (66.10\%) and uplifting (62.00\%), which emphasizes again that they are looking for opportunities to use the programs and scenarios of the cultural heritage of Bulgaria in SPA and wellness therapies and for practicing at the same time other activities, as well as other types of tourism.

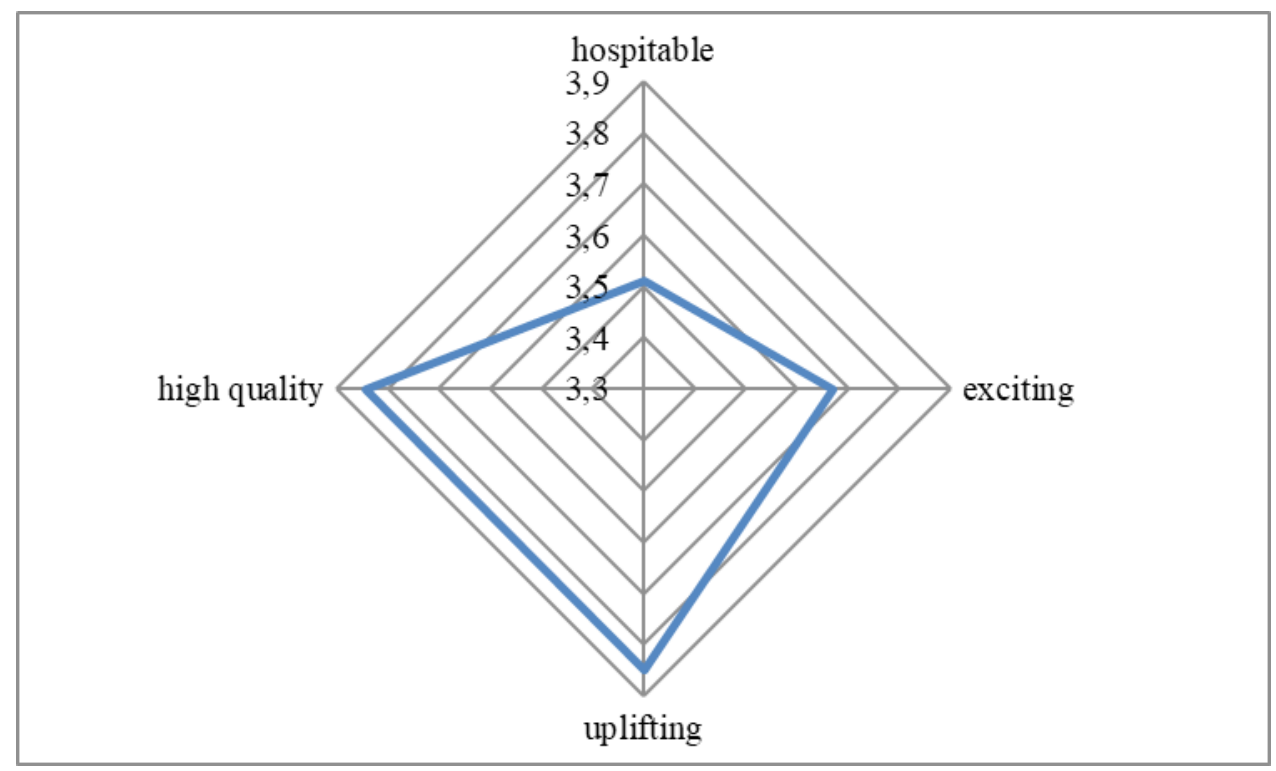

Figure 4: A polar graph for the affective tourist image of SPA and wellness destination Bulgaria (semantic differential scales inhospitable-hospitable, gloomy-exciting, sleepy-uplifting, poor quality-high quality)

\section{CONCLUSIONS}

This study attempts to provide empirical evidence of the affective image of SPA and wellness destination Bulgaria among foreign tourists. The identification of affective image is derived from using descriptive statistics. Consequently, by using Kotler's classification of destination image, it can be concluded that Bulgaria has a positive affective tourist image. By comparing the results with those from other studies, it can be summarized that SPA and wellness tourists perceive destination Bulgaria better than other types of tourists. This can help tourism marketers and ongoing tourism policy of the destination for better understanding the significance of the components of tourist image of Bulgaria.

Further efforts are needed to create and promote products that enhance both cognitive and affective image of Bulgaria towards the high quality, authenticity, tradition and relax. And in turn, the rise of both aspects will improve the overall image of the destination and its repositioning on the penetrating and potential tourist markets.

Among the conclusions that necessitates a new understanding of the positioning of Bulgaria as a distinctive SPA and wellness tourist destination are:

- Positioning based on the strategic management of the messages that are tailored to specific target groups of consumers; 
- Creating a comprehensive image strategy of Bulgaria coordinated and realized with all stakeholders (state institutions, civil, cultural and educational organizations, society, private organizations, etc.); and

- Effective monitoring and public assessment of the achieved results.

The image of the state is not static but is constantly changing under the influence of a number of external and internal factors, that directly or indirectly influence on the affective and cognitive component of the image.

Therefore, building the image implies actively constructing conducted by PRs, and taking into account the expectations and preferences of tourists. Due to the dynamic nature of target groups, maintaining the image of SPA and wellness destination Bulgaria and enriching it with new, desirable elements is an intensive process that is the purpose of further research.

\section{REFERENCES}

[1] Baloglu, S. (1999). A path analytic model of visitation intention involving information sources, socio-psychological motivations, and destination image. Journal of Travel and Tourism Marketing, 8(3), pp. 81-91.

[2] Beerli, A. \& Martín, J.D. (2004). Tourists' characteristics and the perceived image of tourist destinations: a quantitative analysis - A case study of Lanzarote, Spain, Tourism Management, 25, pp. 623-636.

[3] Bigne', J. E., Sa'nchez, M. I., \& Sa'nchez, J. (2001). Tourism image, evaluation variables and after purchase behaviour: Inter-relationship. Tourism Management, 22(6), pp. 607-616.

[4] Echtner, C. \& Ritchie, J., B. (2003). The Meaning and Measurement of Destination Image. The Journal of Tourism Studies, 14 (1), pp. 37-46.

[5] Echtner, C. and Ricthie J. (1993). The Meaning and Measurement of Destination Image. Journal of Tourism Studies, 1991, 2(2), p. 1-13.

[6] Gallarza, M. G., Gil, I., \& Caldero'n, H. (2002). Destination image: Towards a conceptual framework. Annals of Tourism Research, 29(1), pp. 56-78.

[7] Gartner, W. C. (1993). Image formation process. Journal of Travel and Tourism Marketing, 2(2/3), pp. 191-215.

[8] Komppula, R., T. Laukkanen. (2016). Comparing perceived images with projected images - A case study on Finnish ski destinations. European Journal of Tourism Research 12, pp. 41-53.

[9] Leisen, B. (2001). Image segmentation: The case of a tourism destination. Journal of Services Marketing, 15(1), 49-66.

[10] Martin, S. H., \& Del Bosque, I. A. R. (2008). Exploring the cognitive-affective nature of destination image and the role of psychological factors in its formation. Tourism Management, 29(2), pp. 263-277.

[11] RudeŽ, H. N. Affective tourism destination image: the case of Portorož. Tourism and hospitality industry (2014). Congress Proceedings. Trends in Tourism and Hospitality Industry, pp. $245-255$.

[12] Tasci A.D. and Cartner W. (2007). Destination Image and Its Functional Relationships, Journal of Travel Research, 45 (4), p. 413.

[13] Zhang, H. Y. Wu, D. Buhalis. (2017). A model of perceived image, memorable tourism experiences and revisit intention. Journal of Destination Marketing \& Management XXX (XXXX) XXX-XXX, pp. 1-11 